\title{
Oxygen Donor Stabilized Alkaline Earth Metal lodides
}

\author{
Katharina M. Fromm*
}

\begin{abstract}
Alkaline earth metal iodides show ionic behavior in water, but their bonding situation is not that clear in less polar solvents. The alkaline earth metal iodide adducts, i.e. $\left[\mathrm{Ml}_{2}(\mathrm{thf})_{5}\right](\mathrm{M}=\mathrm{Sr}$ and $\mathrm{Ba}),\left[\mathrm{Cal}{ }_{2}(\mathrm{~L})_{4}\right]$ $\left(\mathrm{L}=\right.$ thf, $\left.\mathrm{H}_{2} \mathrm{O}\right)$, $\left[\mathrm{Ba}(\mathrm{OH}) \mathrm{l}\left(\mathrm{H}_{2} \mathrm{O}\right)_{4}\right]$ and [Cal ${ }_{2}(\mathrm{dme})$ (diglyme)] (dme = dimethoxy ethane; diglyme = diethylene glycol dimethyl ether) are presented in this context and their bonding situation is discussed.
\end{abstract}

Keywords: Alkaline earth metals · Covalency · lodides · Ionicity · Structure elucidation

\section{Introduction}

Taking into account the differences in electronegativity of the elements between alkali or alkaline earth metals on one hand and halogens on the other, the alkali and alkaline earth metal halides can be classified as ionic in the solid state and in aqueous solution. In the gas phase however, the binding situation has to be re-evaluated. Thus, a single NaI fragment in the gas phase reveals a resonance behavior of the bond which converts from covalent into ionic [1]. $A b$ initio calculations confirm the covalent character of the bonds in the alkaline earth metal halides and pseudo-halides of the heavier homologues, such as $\mathrm{BaBr}_{2}$, that exhibit bent structures in the gas phase,

${ }^{\star}$ Correspondence: Dr. K.M. Fromm

University of Geneva

Sciences II

30, Quai Ernest Ansermet

$\mathrm{CH}-1211$ Geneva 4

Tel.: +4122702 6032

Fax: +41227026830

E-Mail: katharina.fromm@chiam.unige.ch

www.unige.ch/chiam/fromm whereas a linear arrangement is expected from the classical VSEPR model [2]. This has only recently led to a reformulation of the VSEPR model by Gillespie and Robinson [3] in order to include such exceptional structures and to allow their explanation and prediction.

\section{Results and Discussion}

We have used the principle of systematically and stepwise 'cutting out' structural fragments from a solid state structure with chemical scissors before: With oxygen donor ligands for instance, a complete structural genealogy tree for $\mathrm{BaI}_{2}$ was obtained, starting with a three-dimensional structure and 'cutting' it down via two- and one-dimensional compounds to the zerodimensional $\left[\mathrm{BaI}_{2}(\mathrm{thf})_{5}\right]$ [4]. Similarly, this systematic approach could be applied to barium triflate (triflate $=\mathrm{CF}_{3} \mathrm{SO}_{3}^{-}$) [5], and it was possible to transfer the principle to $\mathrm{CaI}_{2}$ and $\mathrm{SrI}_{2}$. Here, the molecular structures of trans- $\left[\mathrm{CaI}_{2}(\text { thf })_{4}\right]$ and cis$\left[\mathrm{CaI}_{2}\left(\mathrm{H}_{2} \mathrm{O}\right)_{4}\right]$, cis- $\left[\mathrm{Ba}(\mathrm{OH}) \mathrm{I}\left(\mathrm{H}_{2} \mathrm{O}\right)_{4}\right]$, trans$\left[\mathrm{MI}_{2}(\text { thf })_{5}\right](\mathrm{M}=\mathrm{Sr}, \mathrm{Ba})$ as well as trans$\left[\mathrm{CaI}_{2}(\mathrm{dme})\right.$ (diglyme)] will be presented and compared.

\section{Trans-[Cal, $\left.\mathrm{Caf}_{4}\right]$ (1) and cis- $\left[\mathrm{CaI}_{2}\left(\mathrm{H}_{2} \mathrm{O}\right)_{4}\right]$ (2)}

In principle, one would expect similar structures for two compounds written as $\left[\mathrm{CaI}_{2}(\mathrm{~L})_{4}\right]$. In the case of THF as ligand L, only the trans-compound has been observed so far. $\left[\mathrm{CaI}_{2}(\mathrm{thf})_{4}\right]$ (1) was obtained when crystallizing $\mathrm{CaI}_{2}$ from a saturated
THF solution at $-20{ }^{\circ} \mathrm{C}$, in analogy to a species known from literature [6]. With the sterically bulky ligands THF in equatorial and the iodide ions in axial positions, the alkaline earth metal ion reaches a coordination number of six, and the molecules are arranged in a parallel fashion without further strong contacts between the units (Fig. 1a). When the four THF ligands are replaced by water molecules, the cis-compound of $\left[\mathrm{CaI}_{2}\left(\mathrm{H}_{2} \mathrm{O}\right)_{4}\right](2)$ is obtained. The $\mathrm{I}-\mathrm{Ca}-\mathrm{I}$ angle is now $90.7(1)^{\circ}$ compared to $180^{\circ}$ in $\left[\mathrm{CaI}_{2}(\text { thf })_{4}\right]$ (1) (Fig. 1b). The water molecules can interact with the $\mu_{4}$-bridging iodide ligands of the neighbor units in order to build an overall three-dimensional network via hydrogen bonding, as predicted by our established rules for the prediction of the dimensionality of a compound [7]. The $\mathrm{Ca}-\mathrm{I}$ bonds in $\mathbf{1}$ are $3.106 \AA$, but are much longer in 2 with 3.194-3.240 A, indicating the further implication of iodide in hydrogen bonding for compound $\mathbf{2}$. The trans $\mathrm{O}-\mathrm{Ca}-\mathrm{O}$ angle deviates strongly from $180^{\circ}$ at $167.6(5)^{\circ}$, probably due to repulsive interactions between $\mathrm{H}_{2} \mathrm{O}$ and iodide. Also, the trans $\mathrm{O}-\mathrm{Ca}-\mathrm{I}$ angles are at $174.7(5)^{\circ}$ and $175.0(4)^{\circ}$ far from linear. The main interesting feature is the fact that both anions are in vicinal positions, i.e. to obtain the cis-compound, and the question arises why such a structure is more favorable even though the two negative charges must repel each other. Interestingly enough, the transversion of compound $\mathbf{2}$ exists as well [8], with very similar bond length and angles as in compound 1; the four THF ligands of $\mathbf{1}$ being replaced formally by $\mathrm{H}_{2} \mathrm{O}$. It is however unclear, why and when the cis-form 
crystallizes rather than the trans-version. From the synthetic point of view, cis-2 is obtained when crystallizing from diethyl ether in the presence of water whereas the trans compound is obtained from aqueous solution.

\section{$\left[\mathrm{Ba}(\mathrm{OH})\left(\mathrm{H}_{2} \mathrm{O}\right)_{4}\right](3)$}

A cis-arrangement is also found in the compound $\left[\mathrm{Ba}(\mathrm{OH}) \mathrm{I}\left(\mathrm{H}_{2} \mathrm{O}\right)_{4}\right]$ (3) prepared by us [9] as well as Kellersohn et al. [10]. Comparing the chemical formulae, one iodide of the cis-2 compound has formally been replaced by an $\mathrm{OH}^{-}$group in the barium compound. In both compounds the two anions (two $\mathrm{I}^{-}$in 2 , and one $\mathrm{I}^{-}$and one $\mathrm{OH}^{-}$in 3) are in cis-positions to each other, forming angles of $90.7^{\circ}$ and $66.6^{\circ}$, respectively. The larger barium cation completes its coordination number of nine (capped square antiprism) by direct contacts to the neighboring units, leading to two-dimensional layers with the water molecules acting as bridging ligands (Fig. 1c).

These layers are linked via $\mathrm{H}$-bonds to a three-dimensional network. Its $\mathrm{Ba}-\mathrm{I}$ distance is slightly longer than the ionic radii sum, due to the iodide being involved in intramolecular $\mathrm{H}$-bonding to $\mathrm{OH}$ and intermolecular $\mathrm{H}$-bonding to $\mathrm{H}_{2} \mathrm{O}$ of neigh- boring sheets. For the same reasons, an elongation is also observed for the $\mathrm{Ba}-\mathrm{O}$ distances.

\section{Comparison of $\left[\mathrm{BaI}_{2}(\mathrm{thf})_{5}\right](4)$ and $\left[\mathrm{Srl}_{2}(\mathrm{thf})_{5}\right](5)$}

$\left[\mathrm{BaI}_{2}(\text { thf })_{5}\right](\mathbf{4})$ and $\left[\mathrm{SrI}_{2}(\mathrm{thf})_{5}\right](\mathbf{5})$ were both obtained from a concentrated THFsolution by cooling it to $-20{ }^{\circ} \mathrm{C}$. In $\mathbf{4}$, molecular $\mathrm{BaI}_{2}$ is stabilized by five THF molecules (Fig. 2a).

Two iodide atoms surround the barium cation almost linearly with an I-Ba-I angle of $178^{\circ}$, whereas in the gas phase, free molecular $\mathrm{BaI}_{2}$ has an $\mathrm{I}-\mathrm{Ba}-\mathrm{I}$ angle of between

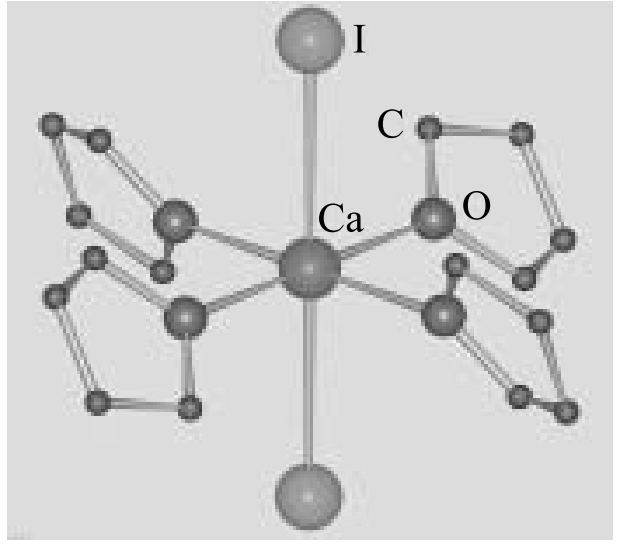

a)

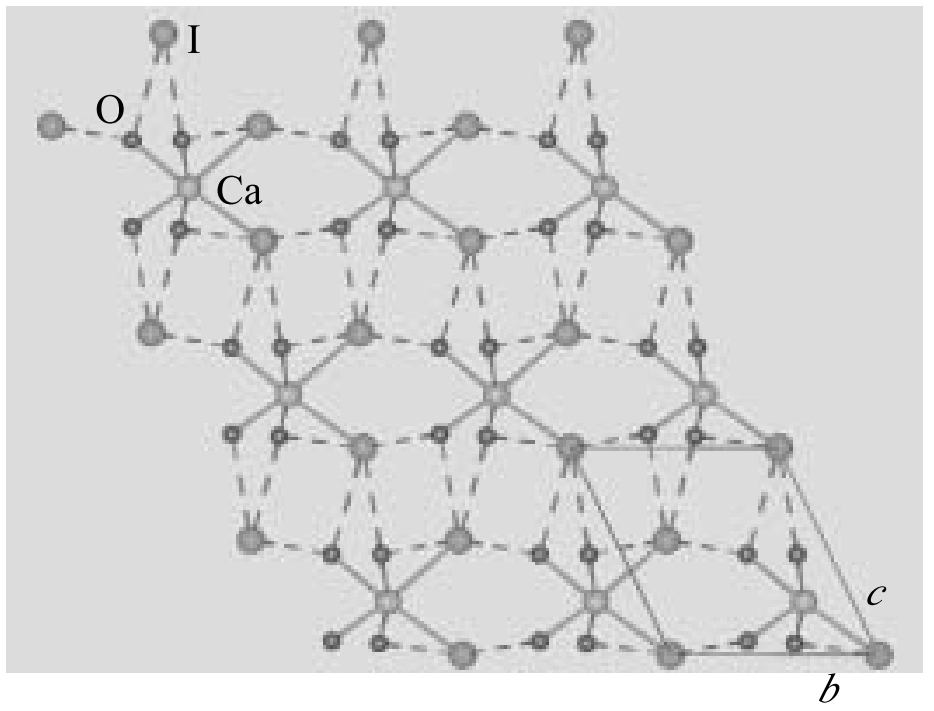

b)

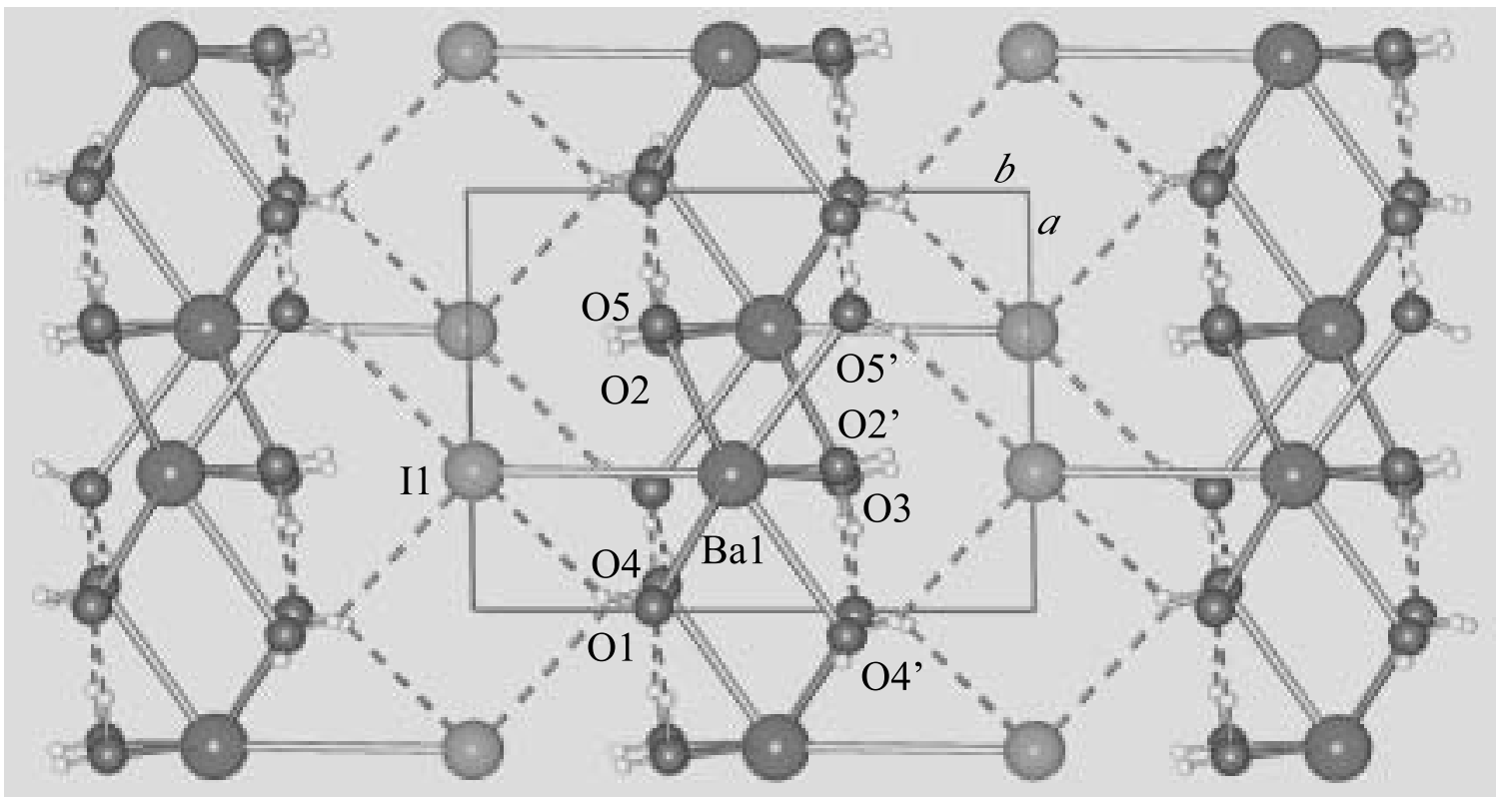

c)

Fig. 1. Molecular unit of $\left[\mathrm{Cal}_{2}(\text { thf })_{4}\right]$ (1) (a); three-dimensional network formed by cis-[ $\left[\mathrm{Cal}_{2}\left(\mathrm{H}_{2} \mathrm{O}\right)_{4}\right](2)$ (b), for a) and b), $\mathrm{H}$-atoms omitted for clarity; packing of the layered structure of $\mathbf{3}$ showing interlayer $\mathrm{H}-\mathrm{I}$ interactions (c) 


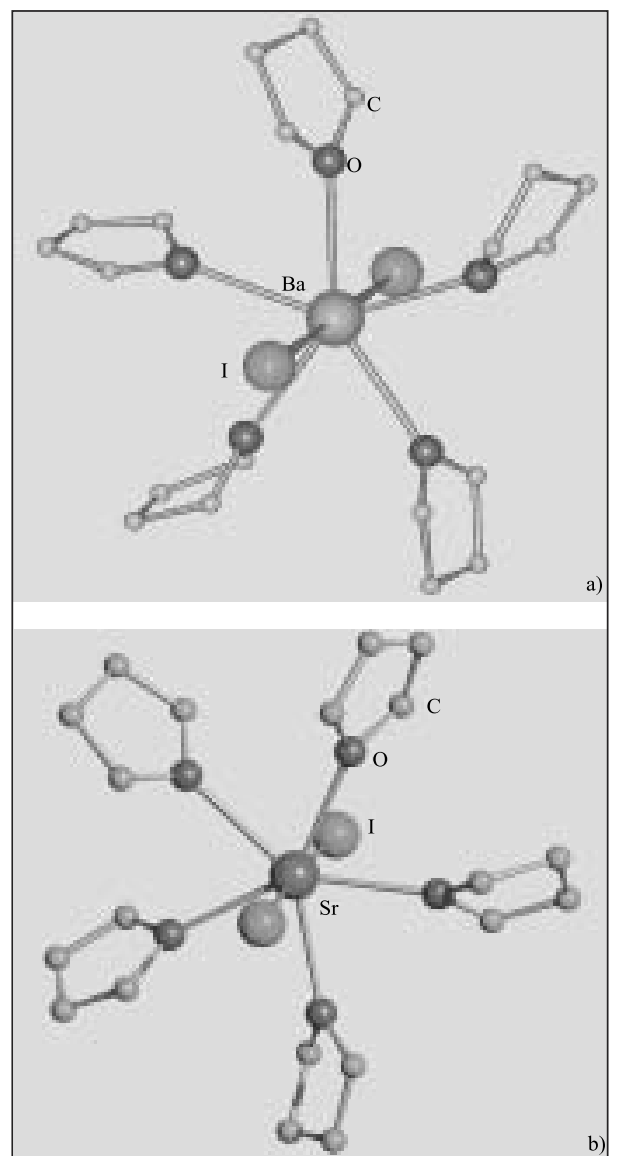

Fig. 2. Molecular structure of $\left[\mathrm{Bal}_{2}(\mathrm{thf})_{5}\right](4)(\mathrm{a})$, and $\left[\mathrm{Srl}_{2}(\text { thf })_{5}\right](\mathbf{5})(\mathrm{b}), \mathrm{H}$-atoms omitted

$102^{\circ}$ and $105^{\circ}$ [2]. The THF donor ligands complete the coordination sphere of barium, occupying the equatorial positions of a slightly distorted pentagonal bipyramid. The coordination number for barium is seven, and that for iodide is one. The structure of compound $\mathbf{5}$ is very similar but with an I-Sr-I angle of $176^{\circ}$ (Fig. 2b) [11]. In both compounds $\left[\mathrm{MI}_{2}(\text { thf })_{5}\right]$ with $\mathrm{M}=\mathrm{Ba}$ and $\mathrm{Sr}$, the alkaline earth metal cation possesses an almost perfect pentagonal bipyramidal coordination sphere, with the halides in axial and the THF molecules in equatorial positions. The M-I bonds are in both cases slightly shorter than the sum of the ionic radii by Shannon [12], the one for strontium in 5 being smaller than the one for barium due to its smaller ionic radius. This is also reflected by the shorter $\mathrm{M}-\mathrm{O}$ bonds. The $\mathrm{O}-\mathrm{M}-\mathrm{O}$ angles have with an average of about $72^{\circ}$ the ideal value for this geometry, whereas the I-M-I angle is smaller in the case of strontium than for the barium compound, possibly indicating a more covalent $\mathrm{M}-\mathrm{I}$ bond for the former. This could also be a consequence of stronger steric interaction of the shorter bonded iodide with the THF molecules in the case of the strontium compound.
Both compounds are zero-dimensional, and the $\left[\mathrm{MI}_{2}(\mathrm{thf})_{5}\right]$ units in the crystal are arranged in a parallel fashion with the iodides pointing towards each other between layers of these units, and no further contacts between the units are observed.

Similar coordination chemistry and structures are known from the lanthanide ions, i.e. the samarium compounds $\left[\mathrm{SmI}_{2}(\mathrm{thf})_{5}\right]$ [13] and $\left[\mathrm{SmI}_{2}(\mathrm{thf})_{5}\right]^{+}[14]$, in which the metal cation is surrounded by two halides and five THF molecules in order to form a pentagonal bipyramidal arrangement.

\section{Structure of [Cal ${ }_{2}($ dme)(diglyme)] (6)}

The calcium ion, as seen in compound 2, seems to be too small to host more than four bulky THF molecules as ligands, whereas strontium and barium cations are able to fix five of them in the above-mentioned iodides $\mathbf{4}$ and $\mathbf{5}$. However, we wanted to test other ethereal ligands in order to investigate if they would stabilize and favor the molecular or the ionic form of $\mathrm{CaI}_{2}$ as well. Polyethers like DME and diglyme were therefore tested on $\mathrm{CaI}_{2}$. The resulting compound obtained from a solution of $\mathrm{CaI}_{2}$ in a 1:1 mixture of both ethers reveals the structure of $\left[\mathrm{CaI}_{2}(\mathrm{dme})\right.$ (diglyme) $]$ (6). The calcium cation reaches a coordination number of seven and is coordinated by two iodide in axial and five oxygen atoms of the polyether ligands in equatorial positions of a severely distorted pentagonal bipyramid. The Ca-I bond lengths of 3.089(1) and 3.139(1) A compare well with the Ca-I distances in $\left[\mathrm{CaI}_{2}(\text { thf })_{4}\right]$ and are shorter than the sum of Shannon radii (Fig. 3) [12].

The I-Ca-I angle $\left(176.52(3)^{\circ}\right)$ is very similar to the one observed in $\left[\mathrm{SrI}_{2}(\mathrm{thf})_{5}\right]$. The $\mathrm{Ca}-\mathrm{O}$ bonds range from 2.415 (3) to 2.467(3) $\AA$, and the $\mathrm{O}-\mathrm{Ca}-\mathrm{O}$ angles of neighboring oxygen atoms vary considerably from the ideal value of $72^{\circ}$ in a regular pentagonal bipyramid with values between $66.94(9)^{\circ}$ (one of the bite angles of digly$\mathrm{me}$ ), and $80.7(1)^{\circ}$ (one of two angles be- tween DME and diglyme). The coordination number of seven for the calcium ion in the form of a pentagonal bipyramid is therefore only possible for calcium with distortion, one oxygen O5 being $0.33 \AA$ out of the least square plane formed by the five oxygen atoms $\mathrm{O} 1$ to $\mathrm{O} 5$. A similar coordination sphere for calcium has only been observed with crown ethers comprising five oxygen atoms, such as 15-crown-5 and its derivatives, as well as in $[\mathrm{Ca}(\mathrm{dme})$ $\left.\left(\mathrm{H}_{2} \mathrm{O}\right)_{3}\right](\mathrm{DME}) \mathrm{I}_{2} \cdot \mathrm{DME}$ [15]. No single crystal data is available for the former compounds, so it is not known whether the calcium atom would sit exactly in the middle of such a macrocyclic ligand [16].

\section{Conclusions}

In the Table, all six compounds are compared to each other, summarizing the most important facts. In the case of organic solvents which are at the same time ligands, one seems to obtain more molecular-type species like in $\mathbf{1}, \mathbf{4}, \mathbf{5}$, and $\mathbf{6}$, whereas in the presence of water, it seems difficult to predict under which conditions which of the compounds, the more molecular transor the more ionic cis-compound, will form. Compounds 1, 4, 5 and $\mathbf{6}$ are well soluble in organic solvents, whereas $\mathbf{2}$ and $\mathbf{3}$, both cis-compounds regarding the anions, are not. The former four compounds possess defined units in the solid state, without further contacts to each other, whereas the latter two are hydrogen bonded or otherwise linked in the three directions of space and form a three-dimensional network. The zero-dimensional compounds behave like molecular compounds on which substitution reactions can take place in a classical way and have found their application as starting materials in reactions described elsewhere to yield supramolecular polymers and cluster compounds of alkaline earth metals [11][17][18].
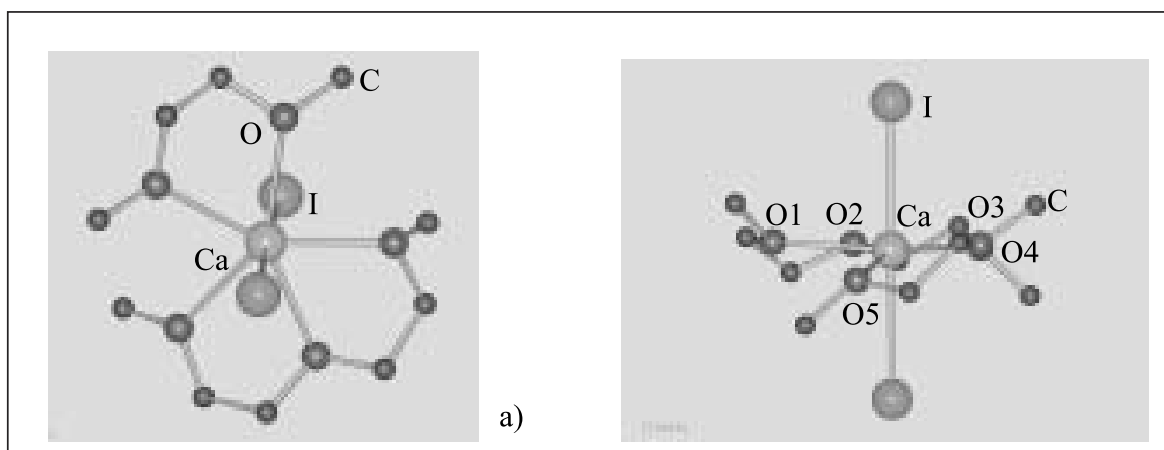

b)

Fig. 3. Views of [Cal ${ }_{2}(\mathrm{dme})($ diglyme)] (6) a) General arrangement of 6; b) $\mathrm{O} 5$ of $\mathbf{6}$ is strongly out of plane; $\mathrm{H}$-atoms omitted for clarity 
Table. The most important structural parameters for the crystal structures of $\left[\mathrm{Cal}_{2}(\mathrm{thf})_{4}\right]$ (1), $\left[\mathrm{Cal}_{2}\left(\mathrm{H}_{2} \mathrm{O}\right)_{4}\right](2),\left[\mathrm{Ba}(\mathrm{OH})\left(\mathrm{H}_{2} \mathrm{O}\right)_{4}\right](3),\left[\mathrm{Bal}_{2}\left(\right.\right.$ thf $\left._{5}\right](4),\left[\mathrm{Srl}_{2}\left(\right.\right.$ thf $\left._{5}\right](5)$, and $\left[\mathrm{Cal}_{2}(\mathrm{dme})\right.$ (diglyme)] (6)

\begin{tabular}{|c|c|c|c|c|c|c|}
\hline & 1 & 2 & 3 & 4 & 5 & 6 \\
\hline$M-I \quad[\AA]$ & 3.106 & $\begin{array}{l}3.194(4), \\
3.240(4)\end{array}$ & $3.6928(8)$ & $\begin{array}{l}3.374, \\
3.3822\end{array}$ & 3.229 & $\begin{array}{l}\text { 3.0895(9), } \\
3.1391(9)\end{array}$ \\
\hline M-O $[\AA ̊]$ & 2.34 & $\begin{array}{l}2.42(2)- \\
2.49(2)\end{array}$ & $\begin{array}{l}2.815(2)- \\
2.863(8)\end{array}$ & $\begin{array}{l}2.696- \\
2.741\end{array}$ & $\begin{array}{l}2.562- \\
2.618\end{array}$ & $\begin{array}{l}2.415(3)- \\
2.467(3)\end{array}$ \\
\hline $\left.\mathrm{I}-\mathrm{M}-\mathrm{I} \quad{ }^{\circ}\right]$ & 180 & $90.7(1)$ & & 178.61 & 176.34 & 176.52(3) \\
\hline $\left.\mathrm{I}-\mathrm{M}-\mathrm{O} \quad{ }^{\circ}\right]$ & 90 av. & $\begin{array}{l}87.7(4) \text { - } \\
94.4(4)\end{array}$ & $\begin{array}{l}66.61(5)- \\
125.79(5)\end{array}$ & $\begin{array}{l}86.10- \\
93.12\end{array}$ & $\begin{array}{l}85.63- \\
92.26\end{array}$ & $\begin{array}{l}82.90(7)- \\
97.52(8)\end{array}$ \\
\hline $\mathrm{O}-\mathrm{M}-\mathrm{O}\left[^{\circ}\right]$ & & $\begin{array}{l}81.7(6)- \\
92.7(7)\end{array}$ & & & & $\begin{array}{l}66.94(9)- \\
80.73(10)\end{array}$ \\
\hline Space group & $\mathrm{P} 2{ }_{1} / \mathrm{c}$ & $P-1$ & $P-1$ & $\mathrm{P} 2{ }_{1} / \mathrm{c}$ & $\mathrm{P} 4_{3} 2_{1} 2$ & $\mathrm{P} 2_{1} / \mathrm{n}$ \\
\hline
\end{tabular}

\section{Experimental}

Synthesis and single crystal data have been published previously [19].

\section{Acknowledgements}

I thank Prof. A.F. Williams and Prof. C. Piguet, both University of Geneva, for their generous support. This work was financed continuously by the Swiss National Foundation. Dr. H. Goesmann, University of Karlsruhe, is thanked for collecting the X-ray data.

Received: February 7, 2003

[1] A.H. Zewail, Angew. Chem. Int. Ed. 2000, 39, 2586-2631.

[2] M. Kaupp, P.v.R. Schleyer, H. Stoll, H. Preuss, J. Am. Chem. Soc. 1991, 113, 6012-6020; M. Kaupp, P.v.R. Schleyer, J. Am. Chem. Soc. 1993, 115, 1120211208 , and references therein.

[3] R.J. Gillespie, E.A. Robinson, Angew. Chem. Int. Ed. 1996, 35, 495-514.

[4] K.M. Fromm, Angew. Chem. 1997, 109, 2876-2878, Angew. Chem. Int. Ed. Engl. 1997, 36, 2799-2801.

[5] K.M. Fromm, G. Bernardinelli, Z. Anorg. Allg. Chem. 2001, 627, 1626-1630.

[6] K.F. Tesh, D.J. Burkey, T.P. Hanusa, J. Am. Chem. Soc. 1994, 116, 2409-2417.

[7] K.M. Fromm, Chem. Eur. J. 2001, 7, 2236-2244.

[8] G. Thiele, D. Putzas, Z. Anorg. Allg. Chem. 1984, 519, 217-224.

[9] K.M. Fromm, H. Goesmann, Acta Cryst. Sect. C. 2000, 56(10), 1179-1180.

[10] T. Kellersohn, K. Beckenkamp, H.D. Lutz, Z. Naturforsch. 1991, 46b, 12791286.

[11] K. Ruhlandt-Senge, K. Davis, S. Dalal, U. Englich, M.O. Senge, Inorg. Chem. 1995, 34, 2587-2592.

[12] R.D. Shannon, Acta Cryst. 1976, A32, 751-767.

[13] W.J. Evans, T.S. Gummersheimer, J.W. Ziller, J. Am. Chem. Soc. 1995, 117(35), 8999-9002.
[14] Z. Xie, K. Chiu, B. Wu, T.C.W. Mak, Inorg. Chem. 1996, 35(20), 5957-5958; Z. Xie, K. Chiu, B. Wu, T.C.W. Mak, Inorg. Chem. 1997, 36(4), 748.

[15] K.M. Fromm, G. Bernardinelli, H. Goesmann, Polyhedron 2000, 19, 1783-1789.

[16] O.A. Raevskii, V.E. Zubareva, I.I. Bulgak, D.G. Batyr, Koord. Khim. 1988, 14, $1193-$ 1196, and references therein.

[17] M.J. Harvey, T.P. Hanusa, V.G. Young, J. Organomet. Chem. 2001, 626, 43-48.

[18] K.M. Fromm, Chem. Comm. 1999, 17, 1659-1660; K.M. Fromm, G. Bernardinelli, H. Goesmann, M.-J. Mayor-Lopez, J. Weber, Z. Anorg. Allg. Chem. 2000, 626, 1685-1691; K.M. Fromm, E.D. Gueneau, H. Goesmann, Chem. Comm. 2000, 21872188.

[19] K.M. Fromm, Cryst. Eng. Comm. 2002, 4(57), 318-322. 